\title{
An Emerging Renaissance in Medical Education
}

Is a renaissance emerging in medical education? One hundred forty-five submissions to the Journal of General Internal Medicine's Education Issue suggests pent-up demand for publication by medical educators. The innovative nature of many submissions suggests that faculty members across the United States and the world are responding creatively to current educational needs. Curricular innovation has in part been spurred by demands of professional organizations, which in turn are responding to societal needs. The Accreditation Council for Graduate Medical Education (ACGME) Outcome Project, which has identified six core competencies, has created the need for increased accountability for documenting proficiency in each of the six competencies (patient care, medical knowledge, interpersonal and communication skills, professionalism, practice-based learning and improvement, and systems-based practice). ${ }^{1}$ This will require increased attention to the evaluation of house staff in general, increased emphasis on the competencies of interpersonal and communication skills and professionalism, and the development of educational approaches to teach and evaluate the new competencies of practice-based learning and improvement and systems-based practice. The Association of American Medical Colleges's (AAMC) core curriculum reflects these priorities. ${ }^{2}$ The American College of Physicians (ACP), ${ }^{3}$ the American Board of Internal Medicine (ABIM), ${ }^{4}$ and others ${ }^{5}$ have shown renewed interest in teaching professionalism. The recent report of the Society of General Internal Medicine's Domain Task Force calls for similar reforms in medical education. ${ }^{6}$ Finally, the ACGME, out of concern for patient care and house staff learning environment, have issued regulations regarding resident work hours, ${ }^{7}$ which in turn have required structural changes in residency training programs. We may need to wait to see the full flowering of a renaissance, but we believe that JGIM's Education Issue provides a broad sampling of work reflecting emerging trends in medical education.

This issue contains 11 articles that describe a broad array of educational innovations designed to address the above needs. Ogrinc et al. ${ }^{8}$ describe an approach to teaching practice-based learning and improvement and systemsbased practice. Houston et al. ${ }^{9}$ have created a communitybased musculoskeletal clinic to provide competency-based learning in a neglected area of internal medicine residency clinical experience and teaching. C.C. Smith et al. ${ }^{10}$ describe a medical procedure service that provides documentation, attending supervision, and standardized evaluation of procedures performed by medical house staff. Torke et al. ${ }^{11}$ have extended the teaching of skills related to end-of-life care to third-year medical students, and Brown et al. ${ }^{12}$ the teaching of behavioral counseling skills to first-year students, skills that are applied by the students in subsequent months in clinical settings. Suchman et al. ${ }^{13}$ describe the early stages of a major project designed to address professionalism and change the hidden curriculum and learning environment at an entire medical school. Sisson et al. ${ }^{14}$ have demonstrated the feasibility of developing and evaluating an Internet curriculum in outpatient medicine that addresses cognitive learning and serves numerous teaching institutions. And Wong et al. ${ }^{15}$ describe the creation of a day-float rotation to enable compliance with resident work hour restrictions. Other articles describe innovative approaches to evaluation. C.S. Smith et al. ${ }^{16}$ have applied the tool of cultural consensus analysis to guide systems-based practice improvements. Zabar et al. ${ }^{17}$ have developed a multistation objective structured teaching evaluation (OSTE) to assess resident teaching skills. Finally, Triola et al. ${ }^{18}$ describe a web-based clinical skills evaluation system that decreases administrative burden, increases accessibility, enables customized reports and feedback, and should be appealing to many training programs.

The seven brief reports and one original article in this issue focus more on understanding or evaluating the efficacy of educational interventions than on their innovativeness per se. In a randomized controlled study, Watkins and Moran $^{19}$ demonstrate that performance in obtaining adequate Pap smears can be improved by the combination of didactics, skills training, and peer comparison feedback. Haist et al., ${ }^{20}$ in a controlled study, demonstrate improved ability to perform sexual history and HIV counseling after a skills workshop involving four simulated patients. In a pre-post study, Buchanan et al. ${ }^{21}$ demonstrate changed attitudes in residents toward homeless patients after participation in a previously described innovative curriculum that involves didactics, observation of community programs and practitioners, case discussion, personal narratives by homeless patients, and reflective journaling. The differences between teacher self-evaluations and learner evaluations are highlighted in the paper by Windish et al. ${ }^{22}$ Holmboe et al., ${ }^{23}$ in their analysis of audiotaped feedback sessions after miniCEXs, identify missed opportunities for encouraging resident self-assessment and developing follow-up or action plans. Hoellein et al. ${ }^{24}$ add evidence supporting work hour restrictions by showing that patients are less satisfied 
when seen in outpatient clinic by residents who are postcall. Rabatin et al. ${ }^{25}$ provide a unique, in-depth qualitative analysis of a successful 1-year mentoring relationship between a senior and a junior clinician-educator faculty member. Finally, Margalit et al., ${ }^{26}$ in an original article, provide evidence from a randomized controlled trial not only that teaching the biopsychosocial model results in improved patient satisfaction and decreased utilization of medical resources, but also that the addition of experiential (role play, review of real videotaped doctor-patient interactions) and self-awareness raising (Balint groups and skilled facilitation of experiential exercises) methods results in better outcomes than didactics and small group discussion alone.

Two perspective articles provide useful advice to clinician-educators. Drawing on their experience at the University of Washington, Pinsky and Fryer-Edwards ${ }^{27}$ explain how having learners maintain working and performance portfolios can promote self-directed learning and self-assessment, and they provide recommendations for successful implementation. Wright and Ziegelstein ${ }^{28}$ review the literature and provide recommendations on writing letters of reference, a task faced by many clinicianeducator faculty.

The two resource articles in this issue provide additional help to clinician-educators. The time is past for nonmethodical, nonscholarly, nonaccountable, educationally naive approaches to curriculum development. Thomas and $\mathrm{Kern}^{29}$ provide an annotated bibliography of Internet resources, a search of which has become an essential early step in curriculum development, in addition to a search of the published literature. The resources section of the journal also includes Knight et al.'s ${ }^{30}$ difficult to classify article that describes the instrument used to rate Internet curricula for the last national SGIM meeting and that also includes a summary of the top five rated curricula. The instrument is an important innovation in development; the Internet curricula are resources for clinician-educators.

In the only review article in this issue, Wamsley et al. ${ }^{31}$ review published data on the efficacy of "resident as teacher" curricula, mostly brief single-shot interventions, and find improvements in self-assessed teaching behaviors and learner evaluations. However, evidence for efficacy becomes more mixed as the evaluation designs become more rigorous, and the outcome measures become more objective. There is also evidence suggesting a decline in skills over time.

The above articles are an impressive array of the innovative and important work being done by today's clinicianeducators to address learner, patient, and societal needs. However, as is true for most educational projects, most of the submissions involved small numbers and only one institution, described single-shot rather than multiphase educational interventions, employed subjective, nonvalidated rather than objective or validated measures for evaluation, used uncontrolled rather than controlled evaluation designs, and did not evaluate the sustainability of educational outcomes or clinical impact. Those chosen for publication were less likely to have these deficiencies, although we purposely published papers in this issue when the innovation was thought to be sufficiently unique and relevant, even if the evaluation component was weak. Reviewing all of the submissions, there did seem to be a tendency for faculty members to pursue innovation with enthusiasm, but perhaps to make evaluation an afterthought. Our advice to educators who are asked to start new programs is to apply a methodical, educationally sound approach to the endeavor. ${ }^{32}$ Immediately set to work on building in an evaluation, and, whenever feasible, build it to address some of the deficiencies noted above and to add substantively to the existing literature on the topic. Ask for sufficient resources. Obtain Institutional Review Board approval. Think about whether colleagues from other institutions might collaborate on the project, thereby improving its generalizability and publishability. SGIM can serve as a catalyst; national and regional meetings provide a festival for medical educators, where educators can meet and plan multi-institutional projects. There are increasing calls to base educational interventions on scientific evidence. ${ }^{33}$ We believe this is an emerging trend in medical education. Educational research, including the evaluation of educational interventions, is what will provide the evidence.

The breadth, importance, and quality of the work published in this issue are especially noteworthy, because most of the work was unfunded. Of those manuscripts accepted for publication, one measure of quality, $42 \%$ had at least partial funding. Of those not accepted, $22 \%$ had at least partial funding (based on a 50\% sample), suggesting that there may be a relationship between funding and the quality of educational work. Most importantly, funding protects faculty time for substantive educational work; it also provides additional resources, such as statistical consultation and research assistants. Research and development in medical education is vastly underfunded at the federal level. ${ }^{34}$ Some educators are dreaming about a National Institute for Medical Education Research. Clinician-educators can advocate for additional funding through research that demonstrates its importance, wellgrounded and executed public education efforts, and responsible political advocacy. In the meantime, some young clinician-educator faculty with appropriate research training and mentorship may want to apply for the career development awards offered by several NIH institutes as well as by some specialty associations. Other faculty may apply directly for research funding. Well-designed projects that target specific disease entities, use validated objective evaluation criteria, and demonstrate impact on patient care through educational interventions are more likely to be funded through these mechanisms. Clinicianeducator scholars can also seek funding from private foundations that support medical education and from private donors/grateful patients. Thomas and Kern's ${ }^{29}$ bibliography 
provides some information on organizations that support educational research and development. Perhaps in a future education issue there will be a resource article that focuses specifically on funding. Finally, clinician-educators can negotiate for some funding from their home institutions. Unfortunately, teaching institutions are under increasing financial pressure, and such funds are becoming increasingly scarce.

What is amazing to us, based on personal observations, is the quality of work that is being accomplished with small grants and seed funding. Advances are occurring in medical education, despite poor funding. External pressures from accrediting bodies are undoubtedly an important factor that spurs teaching institutions to invest more than they otherwise would. Another important factor is dedicated and talented faculty, who despite barriers to promotion, lack of resources, and insufficient protected time, are advancing the field. Perhaps adversity promotes creativity and innovation, as suggested by Irby $^{35}$ in a recent JGIM article. But sufficient sponsorship for research and development in medical education may be a determining factor in whether there is the full flowering of an emerging renaissance. This begs the question of how many young clinicianeducators, with innovative ideas and the ability to accomplish them, are receiving the training they need, the quality of mentorship described in Rabatin et al., ${ }^{25}$ or the funding that will enable them to achieve their full potential? As Levinson said in his classic book on adult development, we should enable individuals to attain their "dream." ${ }^{36}$ In that vein, we hope that this issue helps some clinicianeducators achieve recognition and credit for their work, while being inspiring and useful to many.-William T. BRANCH, JR., MD, Department of Medicine, Emory University School of Medicine, Atlanta, Ga, and DAvid E. KeRN, MD, MPH, Johns Hopkins University School of Medicine, Johns Hopkins Bayview Medical Center, Baltimore, Md.

\section{REFERENCES}

1. Accreditation Council for Graduate Medical Education. Outcomes project: general competencies; 2004. Available at: http:// www.acgme.org/outcome/comp/compFull.asp. Accessed January 2004.

2. Association of American Medical Colleges. GME core curriculum. Available at: http://www.aamc.org/publications/gccm.htm. Accessed March 31, 2004.

3. American Board of Internal Medicine Foundation. ACP-ASIM Foundation, and European Federation of Internal Medicine. Medical professionalism in the new millenium: a physician charter. Ann Intern Med. 2002;136:243-6.

4. Stobo JD, Kohen JJ, Kimball HR, et al. Project Professionalism. Philadelphia, Pa: Project Professionalism, American Board of Internal Medicine; 1995.

5. Stephenson A, Higgs R, Sugarman J. Teaching professional development in medical schools. Lancet. 2001;357:867-70.

6. Larson EB, Finn SD, Kirk LM, et al. The future of general internal medicine: report and recommendations from the Society of General Internal Medicine (SGIM) task force on the domain of general internal medicine. J Gen Intern Med. 2004;19:69-77.

7. Accreditation Council for Graduate Medical Education. Duty hours language; 2004. Available at: http://www.acgme.org/DutyHours/ dutyHoursLang703.pdf. Accessed February 2004.

8. Ogrinc GO, Headrick LA, Morrison LJ, Foster T. Teaching and assessing resident competence in practice-based learning and improvement. J Gen Intern Med. 2004;19:492-5.

9. Houston TK, Connors RL, Cutler N, Nidiry M. A primary care musculoskeletal clinic for residents: success and sustainability. J Gen Intern Med. 2004;19:524-9.

10. Smith CC, Gordon CE, Feller-Kopman D, et al. Creation of an innovative inpatient medical procedure service and a method to evaluate house staff competency. J Gen Intern Med. 2004; 19:510-3.

11. Torke AM, Quest T, Kinlaw K, Eley W, Branch WT Jr. A workshop to teach medical students communication skills and clinical knowledge about end-of-life care. J Gen Intern Med. 2004;19:540-4.

12. Brown RL, Pfeifer JM, Gjerde CL, Seibert CS, Haq CL. Teaching patient-centered tobacco intervention to first-year medical students. J Gen Intern Med. 2004;19:534-9.

13. Suchman AL, Williamson PR, Litzelman DK, Frankel RM, Mossbarger DL, Inui TS. Toward an informal curriculum that teaches professionalism: transforming the social environment of a medical school. J Gen Intern Med. 2004;19:501-4.

14. Sisson SD, Hughes MT, Levine D, Brancati FL. Effect of an Internetbased curriculum on postgraduate education: a multicenter intervention. J Gen Intern Med. 2004;19:505-9.

15. Wong JG, Holmboe ES, Huot SJ. Teaching and learning in an 80-hour work week: a novel day-float rotation for medical residents. J Gen Intern Med. 2004;19:519-23.

16. Smith CS, Morris M, Hill W, et al. Cultural consensus analysis as a tool for clinic improvements. J Gen Intern Med. 2004;19:514-8.

17. Zabar S, Hanley K, Stevens DL, et al. Measuring the competence of residents as teachers. J Gen Intern Med. 2004;19:530-3.

18. Triola MM, Feldman HJ, Pearlman EB, Kalet AL. Meeting requirements and changing culture: the development of a web-based clinical skills evaluation system. J Gen Intern Med. 2004;19:492-5

19. Watkins RS, Moran WP. Competency-based learning: the impact of targeted resident education and feedback on Pap smear adequacy rates. J Gen Intern Med. 2004;19:545-8.

20. Haist SA, Griffith CH III, Hoellein AR, Talente G, Montgomery T, Wilson JF. Improving students' sexual history inquiry and HIV counseling with an interactive workshop using standardized patients. J Gen Intern Med. 2004;19:549-53.

21. Buchanan D, Rohr L, Kehoe L, Glick SB, Jain S. Changing attitudes toward homeless people: a curriculum evaluation. J Gen Intern Med. 2004; 19:566-8.

22. Windish DM, Knight AM, Wright SM. Clinician-teachers' selfassessments versus learners' perceptions. J Gen Intern Med 2004;19:554-7.

23. Holmboe ES, Yepes M, Williams F, Huot SJ. Feedback and the min clinical evaluation exercise. J Gen Intern Med. 2004;19:558-61.

24. Hoellein AR, Feddock CA, Griffith CH III, et al. Are continuity clinic patients less satisfied when the resident is postcall? $\mathrm{J}$ Gen Intern Med. 2004; 19:562-5.

25. Rabatin JS, Lipkin M, Rubin AS, Schachter A, Nathan M, Kalet A. A year of mentoring in academic medicine: case report and qualitative analysis of fifteen hours of meeting between a junior and senior faculty member. J Gen Intern Med. 2004;19:569-73.

26. Margalit AP, Glick SM, Benbassat J, Cohen A. Effect of a biopsychosocial approach on patient satisfaction and patterns of care. J Gen Intern Med. 2004;19:485-91.

27. Pinsky LE, Fryer-Edwards K. Diving for PERLS: working and performance portfolios for evaluation and reflection on learning. $\mathrm{J}$ Gen Intern Med. 2004;19:582-7.

28. Wright SM, Ziegelstein RC. Writing more informative letters of reference. J Gen Intern Med. 2004;19:588-93.

29. Thomas PA, Kern DE. Internet resources for curriculum development in medical education: an annotated bibliography. J Gen Intern Med. 2004;19:599-605. 
30. Knight CL, Sakowski HA, Houghton BL, Laya MB, DeWitt DE. Developing a peer review process for web-based curricula: minting a new coin of the realm. J Gen Intern Med. 2004;19:594-8.

31. Wamsley M, Julian KA, Wipf JE. A literature review of "residentas-teacher" curricula: do courses make a difference? J Gen Intern Med. 2004;19:574-81.

32. Kern DE, Thomas PA, Howard DM, Bass EB. Curriculum Development for Medical Education: A Six-step Approach. Baltimore, Md Johns Hopkins University Press; 1998.
33. Harden RM, Grant J, Buckley G, Hart IR. Best evidence medical education. Adv Health Sci Educ. 2000;5:71-90.

34. Kern DE. Achievements and challenges in medical education. SGIM Forum. 2003;26:1,6-7.

35. Irby DM, Wilkerson L. Educational innovations in academic medicine and environmental trends. $J$ Gen Intern Med. 2003; 18:370-6.

36. Levinson DJ. Seasons of a Man's Life. New York: Random House; 1978. 